\section{Research budgets threatened}

Possinicy over-ambitious British attempts to persuade Brussels to streamline its research programme, a general reluctance to increase budgets in the European Economic Community, and political brinkmanship in Brussels are all conspiring to threaten a decrease in European research spending in 1987 - rather than the neardoubling requested by Community officials earlier this year.

This is the spectre that is beginning to haunt the Brussels research directorate just eight weeks before European ministers are due to decide on a new "framework programme" for research and development, a programme for which Brussels has requested 7,735 million European Currency Units (ECU; $£ 5,500$ million) plus a contingency fund amounting to another 15 per cent, against current spending of over 4,000 million ECU.

The immediate problem is that many existing programmes are coming to the end of their current term. Research to help developing countries, for example, ends in December, and so officially does the European stimulation programme on research in information technology, ESPRIT, although that programme has some unspent cash in its coffers. To deal with a possible hiatus if the framework programme is not agreed in December, Commission research officials had proposed some interim topping-up. But now this has been vetoed from the top by Commission President Jacques Delors.

At stake, according to Delors, is the whole principle of the framework programme, which is in turn embodied in the European Single Act, the reformed treaty governing Community affairs which is still awaiting ratification in most national parliaments. The Single Act for the first time makes science and technology a proper activity of the commission (previously it slid by under the "any other business" Article 235 of the Treaty of Rome), and it demands that ministers agree on an outline enabling programme and budget (the framework) before detailed elements of the programme are fixed. Although the existing framework programme is drafted so that it can go through under Article 235 , Delors has told research commissioner Karl-Heinz Narjes that the principle of framework first, detailed decisions second must be followed.

In practice this is brinkmanship; for $\mathrm{Mr}$ Geoffrey Pattie, Britain's technology minister, who is currently president of the council of research ministers, has nailed his colours to the sorting out of Brussels research by December. Mrs Margaret Thatcher, the British prime minister, is due to speak on the achievements of Britain's six-month presidency of the Council of Ministers a few days after the crucial research council meeting at which the framework programme is due to be decided: if it is not, given Delors' position, she will be describing a near-descent into anarchy.

But meanwhile, Pattic is trying desperately but bravely to get Brussels research plans into the lean, industrially oriented and objectively assessed shape he thinks fit, while at the same time trying to juggle 12 independent national demands about the content and scale of Brussels programmes. The main outstanding issues are, however, the level of funding and degree of assessment of research, on both of which Britain is hawkish, and Delors no doubt feels that a little extra pressure on Britain may result in a slight softening of British resolve, although West Germany and France would still be tough nuts to crack.

Britain may remain equally tough. Pattie outlined his view of Brussels coordinated research last week, in an ESPRIT review meeting; and, although he was speaking so close to the decisive council meeting, he remained ambitiously radical. ESPRIT is widely considered one of Brussels' great successes, in getting wary and nationalistic information-technology businesses involved in joint research. Many in the programme expect its expansion. Pattie dropped strong hints to the contrary. The 1350 -million Alvey programme in a similar field is also coming to an end. A couple of times Pattie indicated the advantages of this programme: it was more rigorously assessed by peer review, and national management could be more efficient. The extension of ESPRIT in its second phase to projects that were much closer to the market place, as the Commission had proposed, also "created real problems" for some member states. Rather than merely extend a successful programme, the Commission should just recognize its success and move the ESPRIT funds into other areas where a stimulus to cooperation would be useful. Here Pattie mentioned not research but investment and marketing. Any second phase of ESPRIT itself would have to be more concerned with small companies than the large ones in which most ESPRIT research is now carried out. Brussels, it seemed, should now steer away from the big boys who now had a real job to do.

European Commission ambitions may thus be curtailed, with West Germany and France following the British line. But there are another nine members of the European Community, more of whom support the Commission proposals than do not, and Delors' brinkmanship could be giving them weapons. Robert Walgate
Plagiarism

\section{Earth-shaking controversy}

\section{Washington}

CONTROVH:RSY is shaking the National Science Foundation (NSF)'s decision to put a $\$ 25$ million earthquake research centre in Buffalo, New York. The award, made in August to the State University of New York (SUNY) at Buffalo, has been sharply criticized by a California team that competed for it. Now a scientist at the California Institute of Technology says parts of SUNY's proposal were copied from his own work, and California senators recently directed the General Accounting Office (GAO) to audit the foundation's award procedure.

NSF's decision initially put the California team's nose out of joint because, along with a greater supply of raw material, California researchers also feel they have an advantage in expertise. (Since 1900, California has had nearly 300 times as many earthquakes measuring more than four on the Richter scale as has New York.) The principal investigator at the University of California, Berkeley, questioned NSF about its review process late in August. Several weeks later, Paul Jennings, a Caltech professor who coauthored the Berkeley proposal, found sections of SUNY's proposal that repeated verbatim some of his contributions to a 1984 report, and he pointed this out to NSF and California senator Pete Wilson.

The foundation then asked SUNY to respond to Jennings' objections, but the university's retort has been muffled by the absence of the proposal's principal author, Robert Ketter. Meanwhile SUNY's provost has told NSF that the parts of the proposal that appear to be copied "constitute less than 2 per cent" of the total 53page work and are not essential to the original science that won the grant. SUNY says that Jennings' work was credited, although not meticulously.

Even if all sides agree that the material was lifted from Jennings' writing, NSF may still be in a quandary as to what to do about it. Jennings thinks the proposal should be disqualified and the review process began again. A SUNY spokesman says the Californians merely have a case of "sour grapes". Wilson and New York Representative Jack Kemp have locked horns over the GAO audit. NSF is conducting an internal investigation to clarify its own review procedure, but has already sent more than $\$ 800,000$ to SUNY investigators.

And all are still awaiting the word from Ketter, who returned from abroad late last week to a situation as tumultuous as the earthquakes he planned to study.

Karen Wright 